\title{
Investigation of Power Losses by Various Brushless Motor Modulation Methods in Motor Mode
}

\author{
Ivan Maradzhiev, Tsvetana Grigorova*, Emil Dinkov \\ Department of Electronics, Technical University of Sofia, Bulgaria
}

Received November 16, 2019; Revised December 24, 2019; Accepted December 30, 2019

Copyright $\bigcirc 2020$ by authors, all rights reserved. Authors agree that this article remains permanently open access under the terms of the Creative Commons Attribution License 4.0 International License

\begin{abstract}
The paper presents a comparative analysis of different modulation techniques for BLDC motor control in terms of several types of losses in the system inverter - BLDC motor in motor mode. The experimental investigated modulation strategies are: unipolar modulation of upper (PWM-TOP or UT) transistors, a bipolar PWM-ON modulation (PWM-ON-BIP), a symmetrical modulation (PWM-PWM), a vector control and non-modulation mode. A simple equivalent circuit for the BLDC motor is used to calculate different losses and the system efficiency. On the basis of the equivalent circuit for the different modulation techniques, simple design procedures are discussed for the determination the eddy current and mechanical viscous loss, the copper loss, the hysteresis and mechanical friction loss, the voltage-drop loss of the inverter transistor and diode. Loss distribution experimental data for the brushless DT4260 motor when operating with different modulations and load torque are presented. On the basis of the obtained values for the efficiency of the studied modulations, references for use in battery powered devices such as electric vehicles, electric scooters and more are made.
\end{abstract}

Keywords BLDC Modulation Techniques, Core Losses

\section{Introduction}

Brushless DC motors are a very good solution for the use in electric drive systems in the industry and transportation. Due to their simple design, reliability and efficiency, they are an alternative to induction and DC motors used in electric vehicles. Power supply the BLDC motors via a voltage source inverter enables the use of various methods for modulating the voltage applied to the motor windings. The application of modulation technique allows reducing the voltage from the power source and facilitating its operation in terms of the value of consumed current.

In $[1,2,6,7]$, studies are performed with different modulations: a unipolar modulation of upper (PWM-TOP or UT) or lower transistors (PWM-BOT or BT), modulations PWM-ON and ON-PWM, a bipolar PWM-ON modulation (PWM-ON-BIP) and symmetrical modulation (PWM-PWM).

Each of these modulation strategies has its advantages and disadvantages. The ability of MOSFET transistors to operate as synchronous rectification results in a smaller voltage drop and reduced inverter losses when the BLDC motor operates in the motor mode. It is established in $[2,8]$, that modulations that allow operation as synchronous rectification are PWM-PWM and PWM-ON-BIP. With PWM-ON-BIP modulation, no negative current peaks are observed when the current is switched from one phase to another, which is a prerequisite for less electromagnetic noise and easier operation of the power source. The other used modulations result in negative current peaks, which are especially large in PWM-PWM modulation.

In order to evaluate the efficiency of these modulation strategies, it is also necessary to analyze the power losses in the system inverter-BLDC. The power losses in the brushless machines are divided into active losses, losses in the stator steel and losses from friction in the bearings and windage. The active losses are directly related to the active resistance of the phase windings and the current flowing through them, also depending on the temperature and the skin effect at high frequencies $[3,4]$.

The aim of the paper is to make a comparative analysis of different modulation techniques for BLDC motor control in terms of power losses in the system inverter BLDC motor. 


\section{Separation of Steel Losses in the Brushless Machine under Different Modulation Techniques}

\subsection{Brushless DC Motors Equivalent Circuit for Loss Calculation}

In order to make a comparative analysis of different modulation techniques for BLDC motors control in terms of power losses in the system inverter - BLDC motor and motor mode, the approach given in [5] is used. Figure 1 shows a simple equivalent circuit for the BLDC motor used to calculate power losses.

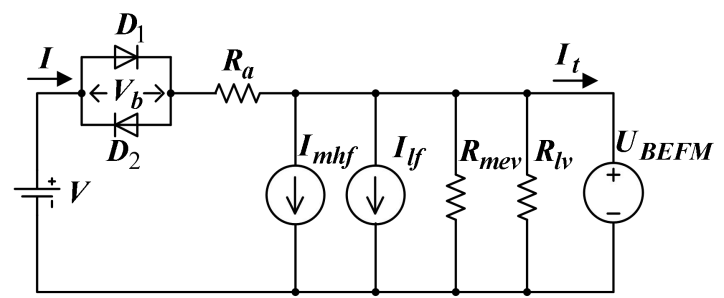

Figure 1. Equivalent circuit for the calculation of losses and efficiency of BLDC motors [5]

The circuit elements are as follows: the resistance $\mathrm{Ra}$ includes BLDC motor armature resistance and the resistance of inverter transistors and/or diodes; the voltage source BEMF illustrates BLDC motor back-EMF; voltage $V$ corresponds to the inverter supply input and current I corresponds to input current respectively. The inverter transistors voltage drop as well as inverter diodes voltage drop are represent through the voltage $V_{b}$ across diodes $D_{1}$ and $D_{2}$.

The eddy current losses are proportional to the square of the induced emf and hence proportional to square of the product of frequency and flux density $[3,4]$. The eddy current loss is given by

$$
P_{e}=k_{e} B_{\max }^{2} \omega_{s}^{2} \text { (W/unit weight) }
$$

where $k_{e}$ is the loss proportionality constant that accounts for volume to weight conversion and all other particular constants associated with magnetic materials, $B_{\max }$ is the peak flux density, and $\omega_{S}$ is fundamental angular frequency of applied voltage.

The mechanical viscous losses are also proportional to square of the motor speed. Thus, these losses are represented through resistors $R_{m e v}$ and $R_{l v}$.

Hysteresis losses, as it is known, depend on the frequency $\omega_{S}$ and maximum flux density $B_{\max }$ [4]. The expression for their value is:

$$
P_{h}=k_{h} B_{\max }^{\alpha} \omega_{s} \quad \text { (W/unit weight) }
$$

where $k_{h}$ is hysteresis loss density proportionality constant and $\alpha$ is known as Steinmetz constant.

Or in other words, hysteresis losses are proportional to the motor speed. The mechanical friction losses are also proportional to the motor speed. Hence, the current source $I_{m h f}$ represents both, motor hysteresis losses and friction losses and the current source $I_{\text {lf }}$ corresponds to friction loss of the load system.

\subsection{Experimental Determination of the Parameters of the Equivalent Circuit}

The BLDC motor used in the experiments is of type DT4260-24-055-04.

The experimental determination of the parameters of the equivalent circuit is accomplished using the following steps:

Step 1: The rotor is locked, i.e. the motor speed is $\omega_{m}=0$. Then, the input voltage is given by:

$$
V=\left|V_{b}\right|+R_{a} I
$$

The voltage $V_{b}$ and resistance $R_{a}$ are determined from the V-I characteristic shown in Figure 2. Using the approximated curve, the following values are received: $R_{a}=1.2871 \Omega$ and $V_{b}=7.74 \mathrm{mV}$.

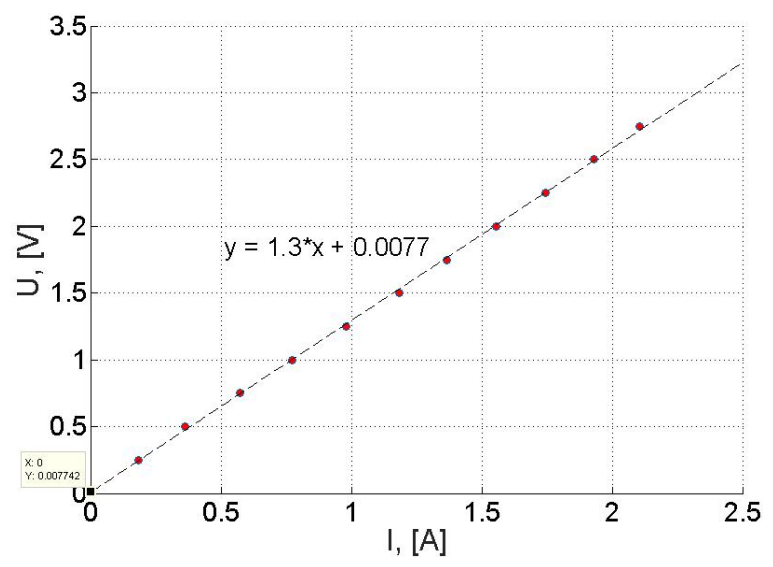

Figure 2. V-I characteristic at the locked rotor

Step 2: The no-load test. For this case the input voltage and current are given by:

$$
\begin{gathered}
V=\left|V_{b}\right|+R_{a} I+U_{B E M F} \\
I=\frac{U_{B E M F} \cdot\left(R_{m e v}+R_{l v}\right)}{R_{m e v} \cdot R_{l v}}+I_{m h f}+I_{l f}
\end{gathered}
$$

Taking into account that

$$
U_{B E M F}=k_{e} \omega_{m}
$$

from the $V-\omega_{m}$ characteristics (Figure 3), the value of the constant is $k_{e}=0.0231[\mathrm{Vs} / \mathrm{rad}]$. 


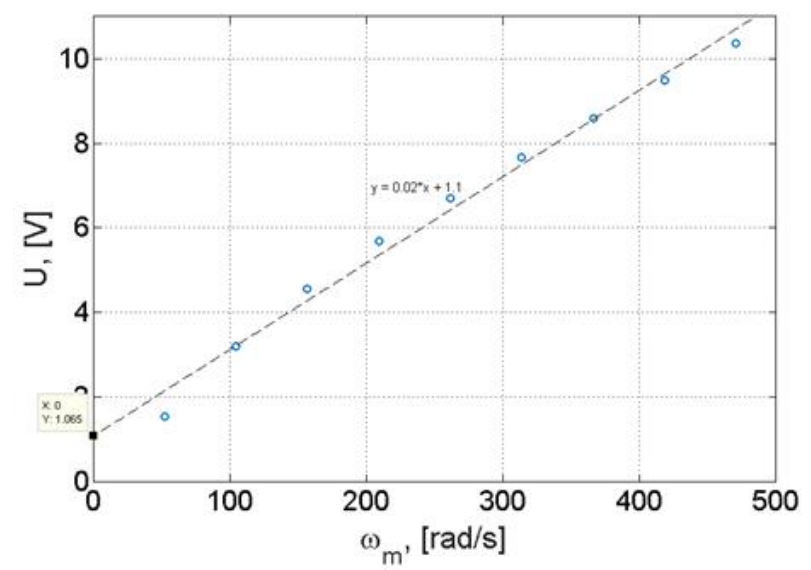

Figure 3. V- $\omega_{\mathrm{m}}$ motor characteristic

Step 3: The equivalent resistance $\left(R_{m e v} \| R_{l v}\right)$ and currents $\left(I_{m h f}+I_{l f}\right)$ can be received from the $I-\omega_{m}$ characteristic.

Figure 4 presents this characteristic for the no-load and nominal speed. The obtained results are as follows: $\left(I_{m h f}+I_{l f}\right)=44.58 m A$ and $\left(R_{m e v} \| R_{l v}\right)=8.06732 \Omega$.

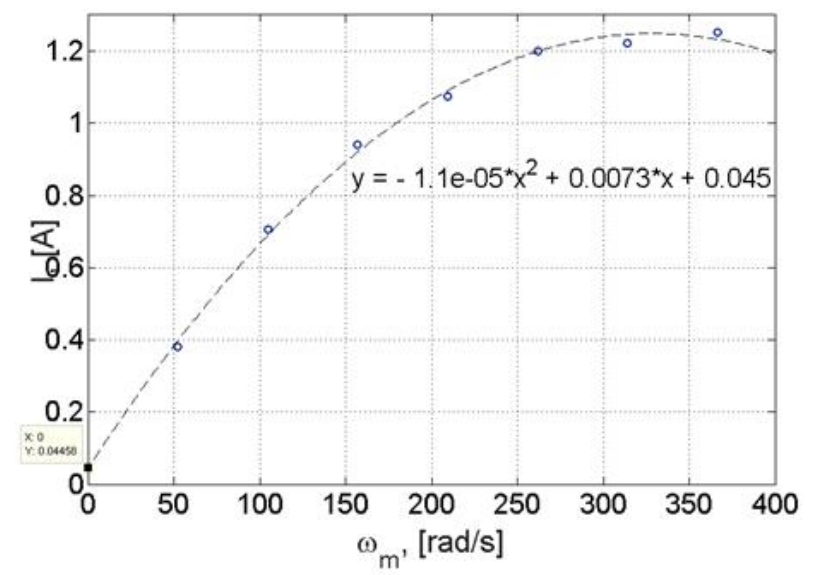

Figure 4. $\quad I-\omega_{m}$ characteristic at no-load and nominal speed

Thus, on the basis of the determined values of the parameters in the equivalent circuit for calculating the losses in the brushless machine, the losses for the selected modulations under different machine loads are calculated.

\subsection{Loss and Efficiency}

When the torque $T_{e}$ and the motor speed $\omega_{m}$ are specified as independent variables, the input voltage $\mathrm{V}$, the input current I, the output power $P_{O}$, the eddy current and mechanical viscous loss $P_{e}$, the copper loss $P_{\mathcal{C}}$, the hysteresis and mechanical friction loss $P_{h}$, the voltage-drop loss of transistor and diode $P_{t}$, and the efficiency $\eta_{i}$ expressed as follows [5],

$$
\begin{gathered}
I_{t}=\frac{T_{e}}{k_{e}} \\
I=\frac{U_{B E M F} \cdot\left(R_{m e v}+R_{l v}\right)}{R_{m e v} \cdot R_{l v}}+I_{m h f}+I_{l f}+I_{t} \\
P_{o}=T_{e} \omega_{m} \\
P_{c}=R_{a} I^{2}
\end{gathered}
$$

The eddy current losses $P_{e}$ are calculated as follows

$$
P_{e}=\frac{U^{2}{ }_{B E M F} \cdot\left(R_{m e v}+R_{l v}\right)}{R_{m e v} \cdot R_{l v}}
$$

The hysteresis losses are given by

$$
P_{h}=U_{B E M F}\left(I_{m_{h f}}+I_{l f}\right)
$$

The transistors and diodes losses are

$$
P_{t}=V_{b} I
$$

Efficiency $\eta_{i}$ is obtained from the dependence

$$
\eta_{i}=\frac{P_{o}}{P_{O}+P_{C}+P_{e}+P_{t}+P_{h}}
$$

Similar $I-\omega_{m}$ curves were taken for the modulation types considered and for vector control method.

\subsection{Experimental Results}

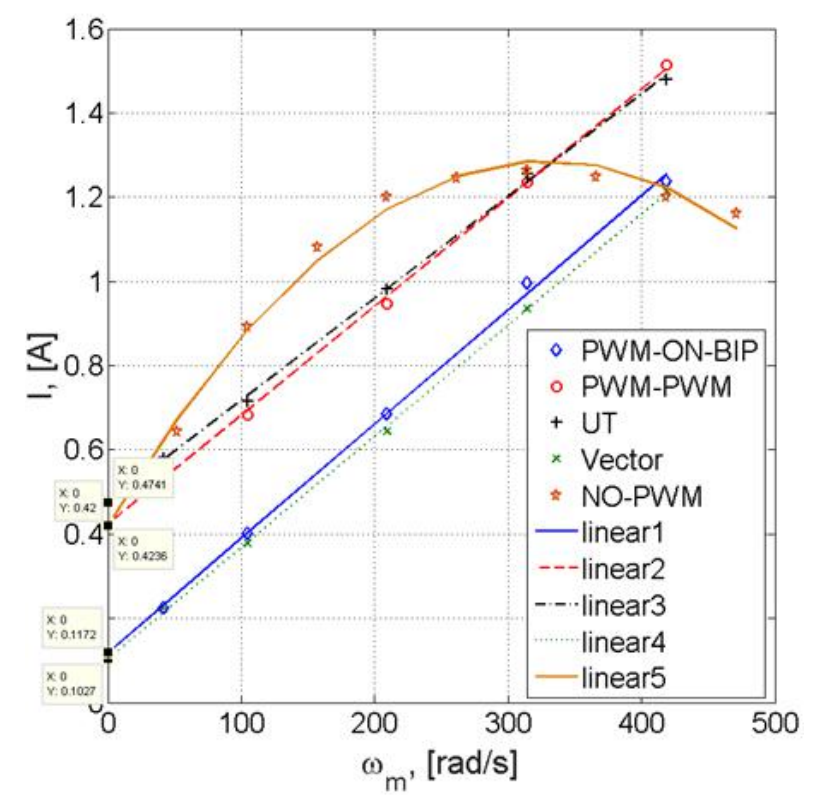

Figure 5. $I-\omega_{m}$ BLDC (DT4260-24-055-04) characteristics for different modulations and load torque $\mathrm{Tload}=0.044 \mathrm{Nm}$

The experimental investigated modulation strategies are: the PWM-ON-BIP modulation, the PWM-PWM 
modulation, the UT modulation, the vector control and non-modulation mode. The brushless DT4260 motor is loaded with the DC generator and the load torque is set to $0.044 \mathrm{Nm}$ and $0.075 \mathrm{Nm}$. In Figure 5, the corresponding curves for $0.044 \mathrm{Nm}$ load torque are presented, and for this load the characteristic is depicted in the case when the speeds are adjusted with the value of the supply voltage, while $\mathrm{D}$ is set to 1 (non-modulation mode). In Figure 6 the characteristics for load torque $0.075 \mathrm{Nm}$ are shown.
The calculated efficiency $\eta_{i}$ using this method differs from that value obtained in the measurements by up to $\pm 5 \%$, which is acceptable for engineering calculations (Table.1). The obtained results show that the vector control and non-modulation modes are characterized with the highest efficiency for the nominal rpm of the brushless DC motor. The non-modulation mode results in less eddy currents generated by the modulation frequency, which also affects their losses.

Table 1. Loss distribution data for the brushless DT4260 motor when operating with different modulations and load torque $\mathrm{T}_{\text {load }}=0.044 \mathrm{Nm}$ and $\mathrm{T}_{\text {load }}=0.075 \mathrm{Nm}$

\begin{tabular}{|c|c|c|c|c|c|c|c|c|c|c|c|c|c|c|c|c|c|c|c|}
\hline & \multicolumn{19}{|c|}{$T_{\text {load }}=0.044 \mathrm{Nm}$} \\
\hline & U & 1 & $\omega$ & $I_{\text {aprox }}$ & $U_{\text {aprox }}$ & $R_{m_{m} \text { ec }} \| R_{\text {I_v }}$ & $k_{e}$ & $m_{m} \mathrm{hf}_{\mathrm{f}} \mathrm{I}_{I_{-}}$ & $T_{e}$ & $R_{a}$ & $V_{b}$ & $\mathrm{I}_{\mathrm{t}}$ & $P_{0}$ & $P_{c}$ & $P_{e}$ & $P_{h}$ & $P_{t}$ & $\eta_{\mathrm{i}}$ & $\eta_{i}-\eta$ \\
\hline & [V] & {$[A]$} & {$[\mathrm{rad} / \mathrm{s}]$} & {$[\mathrm{A}]$} & [V] & {$[\Omega]$} & [Vs/rad] & {$[\mathrm{A}]$} & {$[\mathrm{Nm}]$} & {$[\Omega]$} & [V] & {$[\mathrm{A}]$} & [W] & {$[\mathrm{W}]$} & [W] & [W] & [W] & [\%] & [\%] \\
\hline NO_PWM & 11.08 & 1.2 & \begin{tabular}{|l|}
418.9 \\
\end{tabular} & 1.222 & 11.25 & 12.0649687 & 0.0231 & 0.42 & 0.05013 & 1.287 & \begin{tabular}{|l|}
0.00774 \\
\end{tabular} & 2.17 & 21 & 1.92 & 7.76 & 4.064 & 0.0095 & 60.418 & 1.4183 \\
\hline PWM_ON_BIP & 24.85 & 1.2 & 418.9 & 1.255 & 24.85 & 8.504222297 & 0.0231 & 0.117 & 0.04429 & 1.287 & 0.00774 & 1.92 & 18.6 & 2.03 & 11.01 & 1.134 & 0.0097 & 56.678 & -4.322 \\
\hline PWM_PWM & 24.85 & 1.5 & 418.9 & 1.505 & 24.85 & 8.94775744 & 0.0231 & 0.424 & 0.04513 & 1.287 & 0.00774 & 1.95 & 18.9 & 2.92 & 10.46 & 4.0988 & 0.0117 & 51.941 & 0.9407 \\
\hline UT & 24.85 & 1.5 & \begin{tabular}{|l|}
418.9 \\
\end{tabular} & 1.491 & 24.85 & 9.51529639 & 0.0231 & 0.474 & 0.04462 & 1.287 & 0.00774 & 1.93 & 18.7 & 2.86 & 9.84 & 4.5874 & 0.0115 & 51.934 & 0.9338 \\
\hline \multirow[t]{4}{*}{ Vector } & 24.85 & 1.2 & 418.9 & 1.209 & 24.85 & 8.759827 & 0.0231 & 0.104 & 0.04929 & 1.287 & 0.00774 & 2.13 & 20.6 & 1.88 & 10.69 & 1.0102 & 0.0094 & 60.307 & -1.693 \\
\hline & \multicolumn{19}{|c|}{ Tload $=0.075 \mathrm{Nm}$} \\
\hline & U & 1 & $\omega$ & $I_{\text {aprox }}$ & $U_{\text {aprox }}$ & $R_{m_{\text {_ec }}} \| R_{\text {I_v }}$ & $k_{e}$ & $m_{2} \mathrm{hf}_{\mathrm{f}} \mathrm{I}_{\mathrm{L}}$ & $T_{e}$ & $R_{a}$ & $V_{b}$ & $\mathrm{I}_{\mathrm{t}}$ & $P_{0}$ & $P_{c}$ & $P_{e}$ & $P_{h}$ & $P_{t}$ & $\eta \mathrm{i}$ & $\eta_{n}-\eta$ \\
\hline & [V] & {$[A]$} & {$[\mathrm{rad} / \mathrm{s}]$} & {$[\mathrm{A}]$} & [V] & {$[\Omega]$} & [Vs/rad] & {$[\mathrm{A}]$} & {$[\mathrm{Nm}]$} & {$[\Omega]$} & [V] & {$[\mathrm{A}]$} & {$[\mathrm{W}]$} & {$[W]$} & {$[\mathrm{W}]$} & [W] & [W] & [\%] & [\%] \\
\hline PWM_ON_BIP & 24.85 & 2.3 & 418.9 & 2.298 & 24.85 & 5.04357826 & 0.0231 & 0.38 & 0.0753 & 1.287 & 0.00774 & 3.26 & 31.5 & 6.8 & 18.56 & 3.6721 & 0.0178 & 52.056 & -3.944 \\
\hline PWM_PWM & 24.85 & 2.7 & 418.9 & 2.702 & 24.85 & 7.30272068 & 0.0231 & 1.377 & 0.07685 & 1.287 & 0.00774 & 3.33 & 32.2 & 9.4 & 12.82 & 13.324 & 0.0209 & 47.513 & -0.487 \\
\hline UT & 24.85 & 2.7 & 418.9 & 2.718 & 24.85 & 6.68701099 & 0.0231 & 1.271 & 0.07592 & 1.287 & 0.00774 & 3.29 & 31.8 & 9.51 & 14 & 12.298 & 0.021 & 47.023 & -0.977 \\
\hline Vector & 24.85 & 2.1 & 418.9 & 2.108 & 24.85 & 5.1910434 & 0.0231 & 0.244 & 0.08968 & 1.287 & 0.00774 & 3.88 & 37.6 & 5.72 & 18.04 & 2.361 & 0.0163 & 58.974 & -1.026 \\
\hline
\end{tabular}

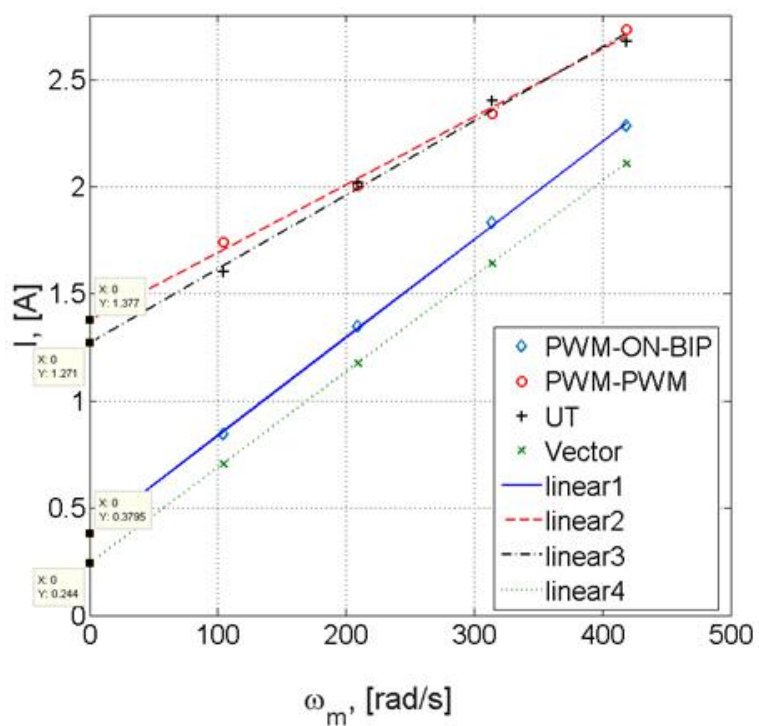

Figure 6. $I-\omega_{m}$ BLDC (DT4260-24-055-04) characteristics for different modulations and load torque Tload $=0.075 \mathrm{Nm}$ 
Figure 7 and Figure 8 present the distribution of losses under the two load modes. The losses in the semiconductor elements $\mathrm{Pt}$ are negligible and therefore are not depicted.

It should be noted that most of the energy losses are from the eddy currents $P_{e}$ in all types of modulation, as the differences under $\mathrm{T}_{\text {load }}=0.044 \mathrm{Nm}$ being within $2 \mathrm{~W}$. The losses at non-modulation mode are significantly smaller. When loading with $\mathrm{T}_{\text {load }}=0.075 \mathrm{Nm}$, there is an increase in the difference of these losses between the different modulations. While for the vector control method and PWM-ON-BIP modulation they are about $18 \mathrm{~W}$, for PWM-PWM and UT modulation they are less than $14 \mathrm{~W}$.

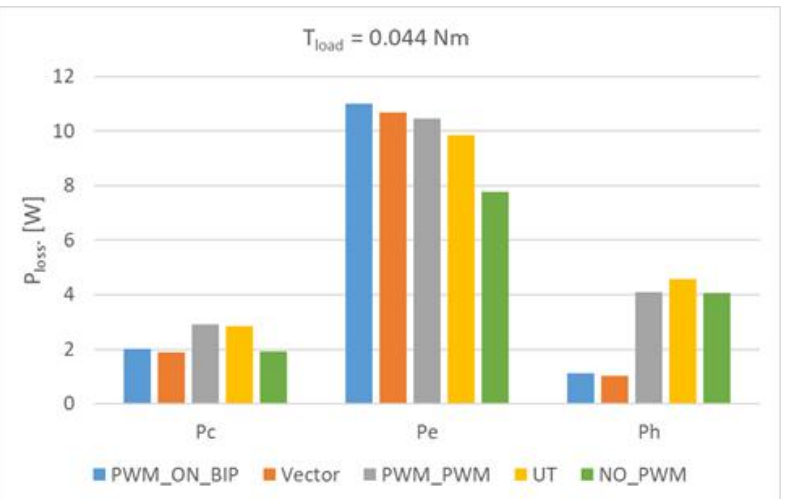

Figure 7. Loss distribution for different modulation techniques $\mathrm{T}_{\text {load }}=$ $0.044 \mathrm{Nm}$

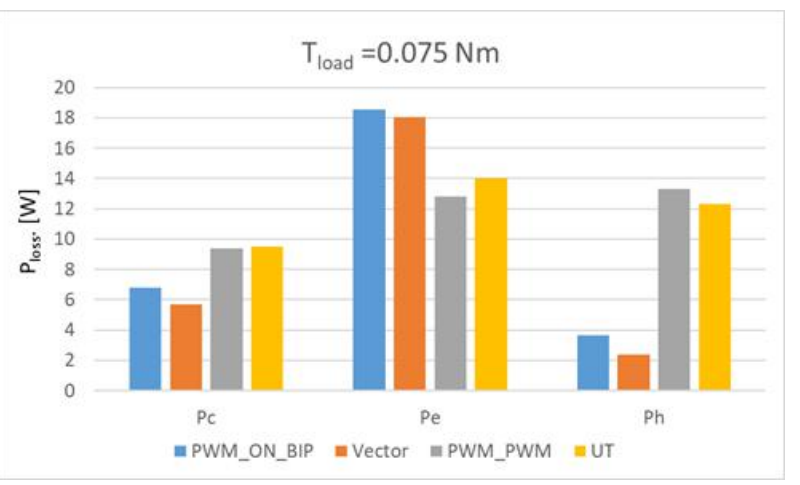

Figure 8. Loss distribution for different modulation techniques $\mathrm{T}_{\text {load }}=$ $0.075 \mathrm{Nm}$

There is a significant difference in the hysteresis losses $P_{h}$. With load $\mathrm{T}_{\text {load }}=0.044 \mathrm{Nm}$, the hysteresis losses at vector control method and PWM-ON-BIP modulation are about $1 \mathrm{~W}$, while for other voltage regulation methods they exceed $4 \mathrm{~W}$. For higher load $\mathrm{T}_{\text {load }}$ $=0.075 \mathrm{Nm}$ this difference becomes drastic, as at the vector control and PWM-ON-BIP modulation are approximately $2 \mathrm{~W}$ and $4.6 \mathrm{~W}$ respectively. For PWM-PWM modulation they are $13.3 \mathrm{~W}$ and $12.3 \mathrm{~W}$ for UT modulation.

The active losses $P_{C}$ also increase with load increase. But for the vector control method, the PWM-ON-BIP modulation and NO_PWM mode these losses are approximately the same and apparently smaller than the same for UT and PWM-PWM modulations. Due to significantly smaller hysteresis losses and active losses, PWM-ON-BIP modulation and the vector control method are more efficient than UT and PWM-PWM modulations. The high PWM-ON-BIP modulation efficiency (4\% to $6 \%$ lower than the much more sophisticated vector control) makes it suitable for use in battery powered devices such as electric vehicles, electric scooters and more.

The efficiency of PWM-ON-BIP modulation under load with $\mathrm{T}_{\text {load }}=0.082 \mathrm{Nm}$ has been investigated, as for rated speed is $57 \%$, and for the same load and using the vector control method, the efficiency is with the same value of $57 \%$. A calculation is made for the distribution of losses at all three loads. All losses increase linearly as the load increases. They are shown in the diagram in Figure 9.

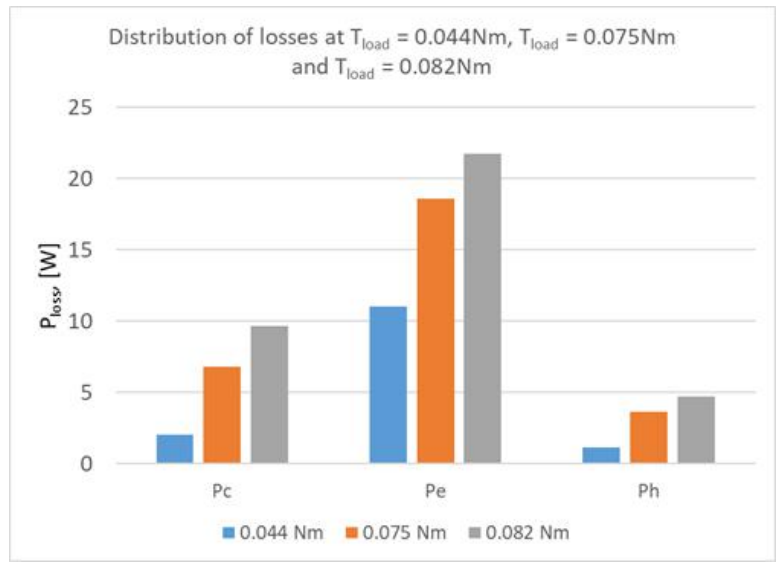

Figure 9. Loss distribution for PWM-ON-BIP modulation under different loads

\section{Conclusions}

It can be concluded, on the basis of the experimentally received results, that the active losses for the vector control method, the PWM-ON-BIP modulation and non-modulation mode are approximately the same and apparently smaller than the same for UT and PWM-PWM modulations. Due to significantly smaller hysteresis losses and active losses, PWM-ON-BIP modulation and the vector control method are more efficient than UT and PWM-PWM modulations.

The efficiency of PWM-ON-BIP modulation is comparable to a more sophisticated vector control which makes it suitable for use in battery powered devices such as electric vehicles, electric scooters and more.

\section{REFERENCES}

[1] C. Cui, G. Liu, K. Wang, A Novel Drive Method for 
High-Speed Brushless DC Motor Operating in a Wide Range, IEEE Transactions on Power Electronics, vol. 30, no. 9 , September 2015

[2] G. Krishnan, K. T. Ajmal, A Neoteric Method Based on PWM ON PWM Scheme with Buck Converter for Torque Ripple Minimization in BLDC Drive, International Conference on Magnetics, Machines \& Drives (AICERA-2014 iCMMD)

[3] R. Krishnan, Electric Motor Drives - Modeling, Analysis, and Control. Prentice Hall, 2001

[4] R. Krishnan, Permanent Magnet Synchronous and Brushless DC Motor Drives, CRC Press, Taylor \& Francis Group 2010

[5] T. Ishikawa, T. Tsuji, S. Hashimoto and N. Kurita. A Simple Equivalent Circuit Calculation for Efficiency of Brushless DC Motors, Journal of International Conference on Electrical Machines and Systems Vol. 3, No. 1, pp. 54 60, 2014

[6] W. Brown, Brushless DC Motor Control Made Easy, Microchip Technology Inc., $2002-2011$

[7] R. Condit, Brushed DC Motor Fundamentals, Microchip Technology Inc., 2010

[8] I. Maradzhiev. Investigation Of Types Of Modulations Used In A Converter That Drives A Brushless Dc Machine In An Electric Vehicle, Ph. D Thesis, 2018 